\title{
New method for preparing purity $\beta$-D-glucans (beta-Glucan) from baker's yeast (Saccharomyces cerevisiae)
}

\author{
Pham Ngoc Khanh ${ }^{1,2, *}{ }^{,}$, Nguyen Duy Nhut ${ }^{3}$, Nguyen Manh Cuong ${ }^{1}$
}

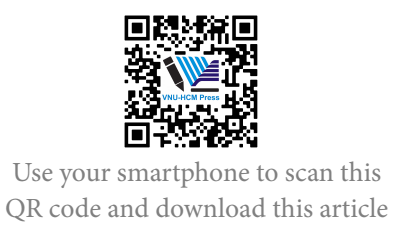

${ }^{1}$ Institute of Natural Products Chemistry (INPC), Vietnam Academy of Science and Technology (VAST), Cau Giay, Hanoi, Vietnam

${ }^{2}$ College of Pharmacy, BMC Campus, Dongguk University, Goyang, South Korea

${ }^{3}$ Nhatrang Institute of Technology Research and Application (NITRA), Vietnam Academy of Science and Technology (VAST), Nha Trang, Vietnam

\section{Correspondence}

Pham Ngoc Khanh, Institute of Natural Products Chemistry (INPC), Vietnam Academy of Science and Technology (VAST), Cau Giay, Hanoi, Vietnam

College of Pharmacy, BMC Campus, Dongguk University, Goyang, South Korea

Email: khanhngoclila@gmail.com

History

- Received: 2020-04-01

- Accepted: 2020-08-21

- Published: 2020-09-04

DOI : 10.32508/stdj.v23i3.2051

\section{Check for updates}

\section{Copyright}

(๑) VNU-HCM Press. This is an openaccess article distributed under the terms of the Creative Commons Attribution 4.0 International license.

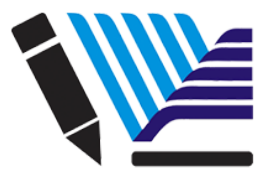

VNU-HCM Press

\begin{abstract}
Introduction: $\beta$-D-glucans (beta-Glucan), a water-soluble polysaccharide with diversity physiological activities for applications in food and pharmaceutical industries. Methods: In this paper, we report the use of ionic liquid 1-butyl-3-methyl-imidazolium chloride [BMIM]Cl on the extraction and isolation of $\beta$-glucan from baker's yeast Saccharomyces cerevisiae. The $\beta$-D-glucans precipitated by adding water into the solution and obtained by filtration or centrifugation were pure, cleaned, and free of cell membranes. Results: The beta-glucan was obtained as white precipitates after adding water into the mixed solution. The 1D and 2D-NMR spectrum and titration methods applied for qualitative and quantitative determination showed that the beta-glucan product contained $78.2 \%$ 1,3- $\beta$-D glucan with $98.4 \%$ purity. Conclusion: This method can be used to prepare purified beta-glucan from baker's yeast.

Key words: $\beta$-D-glucans, Saccharomyces cerevisiae, lonic liquid, 1-butyl-3-methyl-imidazolium chloride $[\mathrm{BMIM}] \mathrm{Cl}$
\end{abstract}

\section{INTRODUCTION}

$\beta$-D-glucans (beta-glucan) are polysaccharide consisting of glucose molecules, linked by $\beta-(1-3)$ and/or $\beta$-(1-6) linkages (IUPAC Recommendations 1995) with physiological diversity activities for applications in food and pharmaceutical industries ${ }^{1}$. It is wellknown to be the strongest natural immune-enhancing compound $^{2}$. $\beta$-D-glucans are anti-carcinogenic agents through the activation of macrophages, T-cells, and NK cells for defending the immune system ${ }^{3} . \beta$ D-glucans are found in the cell walls of many microorganisms, including plants, such as oats and barley, bacteria, fungi, algae, lichens, and yeast ${ }^{4}$. The cell wall of Saccharomyces cerevisiae yeast is one of the important b-glucan source ${ }^{5}$.

The extremely low solubility of yeast $\beta$-d-glucan in water due to the relatively strong intermolecular hydrogen bonds between hydroxyl groups of the glucose units in the $\beta$-D-glucan chains causes these products difficult to extract from yeast and therefore limits its application $^{5}$. Thus, using ionic liquid composed of full of cations and anions, high polarity, and lowmelting-point salts are able to increase the solubility of yeast - D-glucan and consequently increase the yield of b-glucan extracted from yeast ${ }^{5}$. In order to obtain $\beta$-D-glucan with high yield and high purity for application as a pharmaceutical product, in this paper, we described method using the ionic solution to produce beta-glucan from baker's yeast (Saccharomyces cerevisiae). The $\beta$-D-glucans precipitated by adding water into the solution and obtained by filtration or centrifugation were pure, cleaned, and free of cell membranes.

\section{MATERIALS AND METHODS}

Beta-D-glucan 98\%, 1-chlorobutane, 1methylimidazole, $\mathrm{K}_{3} \mathrm{Fe}(\mathrm{CN})_{6}, \quad \mathrm{NaOH}, \quad \mathrm{H}_{2} \mathrm{SO}_{4}$ were purchased from Sigma-Aldrich (USA) and used as obtained. Acetonitrile and ethyl acetate (Merck) were distilled over phosphorus pentoxide $\left(\mathrm{P}_{2} \mathrm{O}_{5}\right)$ and stored over molecular sieve $4 \mathrm{~A}$ before use. $1 \mathrm{D}$ and 2D-NMR spectra were measured on a Bruker AVANCE 500 spectrometer in deuterated solvents as DMSO $-d_{6}, \mathrm{CD}_{3} \mathrm{COOD}-d_{4}$ or $\mathrm{D}_{2} \mathrm{O}-\mathrm{d}_{2}$ (Sigma-Aldrich (USA)).

\section{Preparation of ionic solution [BMIM]Cl}

The ionic solution 1-butyl-3-methyl-imidazolium chloride [BMIM]Cl was prepared according to the method of Dupont et al. ${ }^{6}$. Briefly, $150 \mathrm{~g} 1$ methylimidazole, $80 \mathrm{~mL}$ acetonitrile, and $220 \mathrm{~g} \mathrm{1-}$ chlorobutane were added in a $2-\mathrm{L}$, three-necked, round-bottomed flask and refluxed at $80{ }^{\circ} \mathrm{C}$ in a heating oil bath for $48 \mathrm{~h}$. The excessive volatile material was removed by vacuum distillation. The remaining light-yellow oil was re-dissolved in dry 
acetonitrile $(250 \mathrm{~mL})$, and the solution was dropwise added into a well-stirred solution of dry ethyl acetate $(1000 \mathrm{~mL})$. One seed crystal of 1-butyl-3methylimidazolium chloride was added, and the flask was cooled at $-30^{\circ} \mathrm{C}$ for $2 \mathrm{hr}$ to initialize the exothermic crystallization process of [BMIM]Cl. Remove the supernatant solution through a filter cannula under pressure buildup from dry nitrogen. Dry the remaining white solid under reduced pressure $(0.1 \mathrm{mbar}$, $0.001 \mathrm{~mm})$ at $30^{\circ} \mathrm{C}$ overnight to afford [BMIM] Cl $282.5 \mathrm{~g}(\sim 87 \%), \mathrm{mp} 65-67^{\circ} \mathrm{C}$. The products were identified using ${ }^{1} \mathrm{H}$-NMR spectrometer and compared the spectroscopic data with those in published literature.

\section{Extraction of beta-glucan from baker's} yeast (Saccharomycess cerevisiae)

$5 \mathrm{~g}$ dry baker's yeast powder Saf-Viet was added in $100 \mathrm{~g}$ [BMIM]Cl in a $500 \mathrm{ml}$ glass beaker. Stirred the solution in $30 \mathrm{~min}$ at $80{ }^{\circ} \mathrm{C}$ until all powder was solved in [BMIM]Cl in order to obtain a clear solution. Added $200 \mathrm{ml}$ water and stirred for another 15 min. Crude beta-glucan was separated as precipitates, filtered and washed 3 times with hot water to remove impurity substances and dried overnight at $50{ }^{\circ} \mathrm{C}$ to obtain pure beta-glucan. $125 \mathrm{~g} \beta$-D-glucan was obtained from $1 \mathrm{~kg}$ dried yeast, so yield $\sim 83.5 \%$ (compared to beta-glucan originally contained in the yeast).

\section{Determination of $\beta$-D-glucan content in the product}

An accurate weigh of $0.100 \mathrm{~g}$ of the standard $\beta$-glucan (Sigma-Aldrich), the baker's yeast, and beta-glucan product were dissolved in $2 \mathrm{ml}$ ice-cold $\mathrm{KOH} 2 \mathrm{M}$ in three tightly screwed $15 \mathrm{ml}$ centrifuge tubes. Vortex for 20 minutes to dissolve all impurities as $\alpha$-glucan, mannoprotein, glycogen. Centrifugation and remove the supernatant. The precipitate was washed with $2 \mathrm{ml}$ ice-cold distilled water $(2 \mathrm{x})$. Centrifuge and remove the washing solution.

The samples were then hydrolyzed with $2.0 \mathrm{ml}$ icecold $\mathrm{H}_{2} \mathrm{SO}_{4} 12 \mathrm{M}$ solution. Vortex well in ice for 10s. Add $10 \mathrm{ml}$ distilled water and incubate at 100 ${ }^{o} \mathrm{C}$ for $2 \mathrm{~h}$. The solutions were then cooled to RT, filtered to remove impurities, and slowly neutralized with $\mathrm{NaOH} 5 \%$ in the presence of 3 drops of methyl red until a yellowish appeared. Add water to $100 \mathrm{ml}$ in volumetric flask and mix (Solution A). Add $10 \mathrm{ml}$ of $\mathrm{K}_{3} \mathrm{Fe}(\mathrm{CN})_{6} 1 \%$ solution and $2.5 \mathrm{ml} \mathrm{NaOH} 2.5 \mathrm{~N}$ in a flask, (boil the mixture) and titrate with sample solution A containing reducing sugar from the burette.
The initial solution had a lemon-yellow color of potassium ferrocyanide. The titration stops were determined when the lemon yellow disappeared, the solution became colorless or transparent for about $30 \mathrm{sec}$ onds and then turned to the very pale straw yellow color of ferricyanide, consuming $\mathrm{V}_{1}(\mathrm{ml})$ of the sample solution. Do the same procedure with baker's yeast and beta-glucan product samples, consuming $\mathrm{V}_{0}$, and $\mathrm{V}_{2}$. The reaction occurred as shown as following ${ }^{7}$

$$
\begin{aligned}
& \text { Glucose }+\mathrm{K}_{3} \mathrm{Fe}(\mathrm{CN})_{6}+\mathrm{NaOH} \\
& \rightarrow \mathrm{NaK}_{3} \mathrm{Fe}(\mathrm{CN})_{6}+\text { oxidation products }
\end{aligned}
$$

$\mathrm{V}_{0}, \mathrm{~V}_{1}$, and $\mathrm{V}_{2}(\mathrm{ml})$ were the volumes of hydrolyzed $\beta$-D-Glucan needed to reduce $\mathrm{Fe}^{3+}$ in $\mathrm{K}_{3} \mathrm{Fe}(\mathrm{CN})_{6}$ to $\mathrm{Fe}^{2+}$ of the standard (98\%, Sigma-Aldrich), baker's yeast and beta-glucan product samples, respectively. The average volumes of 3 times titrations were used for calculation according to formulas:

The glucan amount was presented in the baker's yeast $\mathrm{P}_{1}=0.98 \times \mathrm{V}_{0} / \mathrm{V}_{1}$.

The amount of beta-glucan was presented in the products $\mathrm{P}_{2}=0.98 \times \mathrm{V}_{0} / \mathrm{V}_{2}$.

\section{RESULTS}

\section{The ionic liquid [BMIM]CI}

The obtained synthetic ionic liquid was examined by ${ }^{1} \mathrm{H}-\mathrm{NMR}$ spectrum (Figure 1).

In the spectrum showed the presence of proton signal of one methyl group $\left(-\mathrm{CH}_{3}\right)$ at $\delta_{H}(\mathrm{ppm}) 0.84(3 \mathrm{H}, \mathrm{t}$, $\left.\mathrm{H}-4^{\prime}\right)$ and three successive methylene groups $\left(-\mathrm{CH}_{2}-\right)$ belonging to a butyl group at $\delta_{H}(\mathrm{ppm}) 1.24(2 \mathrm{H}, \mathrm{m}$, $\left.\mathrm{H}-3^{\prime}\right), 1.78\left(2 \mathrm{H}, \mathrm{m}, \mathrm{H}-2^{\prime}\right)$ and at $\delta_{H}(\mathrm{ppm}) 4.12(2 \mathrm{H}$, $t, H-1$ '). In addition, the spectrum also showed the presence of three typical - $\mathrm{CH}$ - signals of one imidazole ring at $\delta_{H}(\mathrm{ppm}) 7.36(1 \mathrm{H}, \mathrm{s}, \mathrm{H}-5), 7.41(1 \mathrm{H}, \mathrm{s}$, $\mathrm{H}-4)$ and $8.65(1 \mathrm{H}, \mathrm{s}, \mathrm{H}-2)$, and finally, the proton of a methyl group associated with an electrophile center of the ring at $\left.\delta_{H}(\mathrm{ppm}) 3.82(3 \mathrm{H}, \mathrm{s}, \mathrm{H}-1)^{\prime \prime}\right)^{6}$. Compare to the literature; it can be established that the obtained product was 1-butyl-3-methyl-imidazolium chloride [BMIM] $\mathrm{Cl}^{6}$. This compound was then used to prepare ionic liquid to extract beta-glucan from the baker's yeast.

\section{Beta-glucan product}

The beta-glucan extracted from baker's yeast (Saccharomycess cerevisiae) using the synthetic ionic liquid [BMIM]Cl was checked qualitatively by $1 \mathrm{D}$ - and 2D-NMR spectrum. HSQC spectrum of the product (Figure 2), showing the cross-peak of carbon signals at $\mathrm{d}_{C}(\mathrm{ppm}) 103.4(\mathrm{C}-1), 70.1(\mathrm{C}-2), 85.7$ (C-3), 69.1 $(\mathrm{C}-4), 76.8$ (C-5), and 61.9 (C-6) of $1,3-\beta$-D-glucan, 


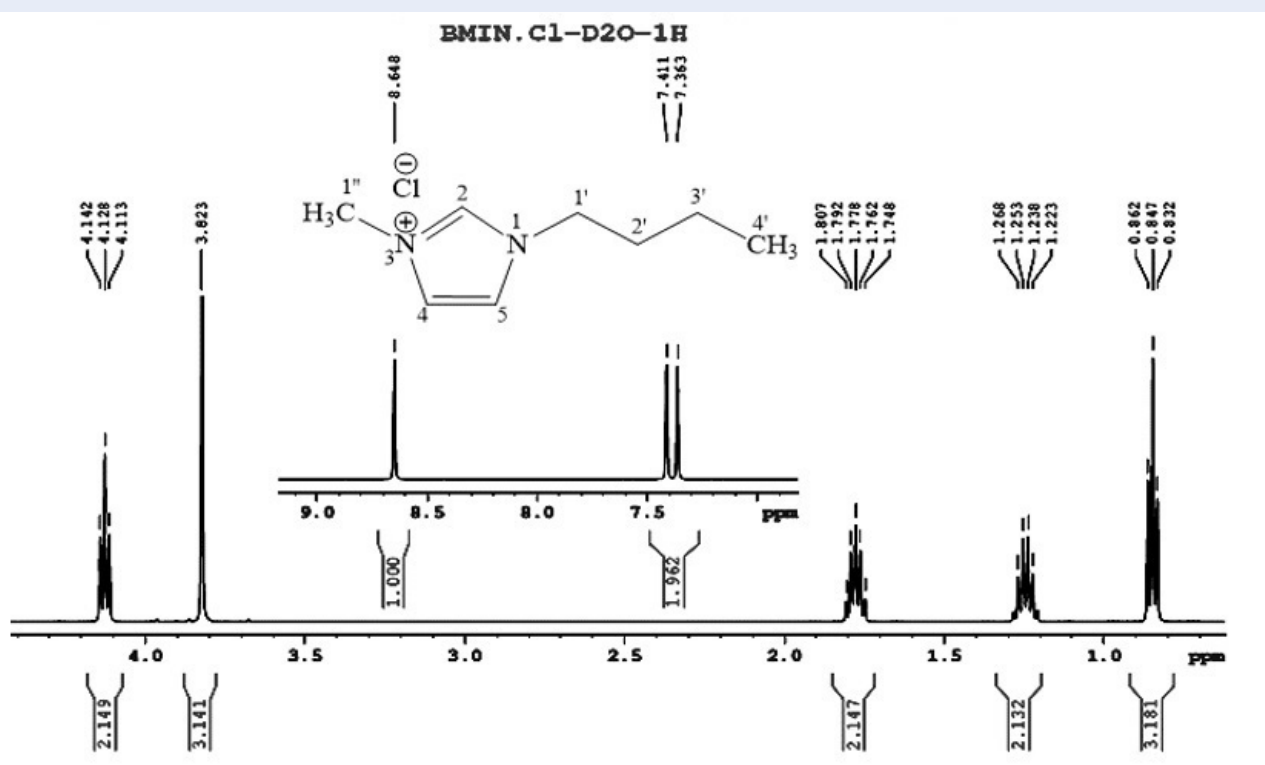

Figure 1: ${ }^{1} \mathrm{H}-\mathrm{NMR}$ spectrum $\left(\mathrm{D}_{2} \mathrm{O}\right)$ of the ionic synthetic liquid 1-butyl-3-methyl-imidazolium chloride [BMIM]Cl.

to corresponding protons at $\delta_{H}(\mathrm{ppm}) 5.15(\mathrm{H}-1), 4.0$ (H-2), $4.2(\mathrm{H}-3), 3.8(\mathrm{H}-4), 3.6(\mathrm{H}-5), 4.3(\mathrm{H}-6)$ and $4.1\left(\mathrm{H}-6\right.$ '), respectively ${ }^{8}$. The water signal appeared at $\delta_{H}$ 4.7. ppm $^{9}$ (Figure 2).

Cell-wall glucans are mainly composed of $1,3-\beta$-Dglucan, mannan (a common carbohydrate in baker yeast), and 1,6- $\beta$-D-glucan.

Compare to the paper published by Ohno et al. ${ }^{8}$ and Gonzalez et al. ${ }^{10}$, whose $\beta$-glucan product had a proton peak of water trace at $\sim 4.2 \mathrm{ppm}$ and mannan signal at $\delta_{H}>4.9 \mathrm{ppm}\left(\right.$ in $\left.\mathrm{D}_{2} \mathrm{O}-d_{2}\right)$. Calibrated the water peak of our measurement spectrum in $\mathrm{CD}_{3}$ COOD- $d_{4}$ from $4.7 \mathrm{ppm}$ to $\sim 4.2 \mathrm{ppm}$, then no signals belonging to mannan carbohydrate impurity at $\delta_{H} 4.9-5.5 \mathrm{ppm}$ were found, indicating that our $\beta$-glucan product was clear from mannoprotein. However, the product contains 1,6- $\beta$-D-glucan with the proton signal of $\mathrm{H}-1$ at $\delta_{H} \sim 4.9-5.0$ ppm (Figure 3). Thoroughly, the ${ }^{1} \mathrm{H}-$ NMR spectrum showed that signals attributable to the 1,3 - $\beta$-D-glucan were mostly observed, while those of the mannan and the $1,6-\beta$-D-glucan were hardly visible (Figure 3).

Based on peak integration in our ${ }^{1} \mathrm{H}-\mathrm{NMR}$ spectrum, the proportion ratio of this 1,6beta-glucan / 1,3betaglucan was $0.186: 1.000(1.302: 7.000) \cong 15.6 \% /$ $84.4 \%$ (Figure 3 ). These facts suggested that the extraction by ionic liquid was rather selectively to obtain 1,3- $\beta$-D-glucan.

\section{Determination of glucan content in the product}

The glucan content in the obtained product was determined using titration method with $\mathrm{K}_{3} \mathrm{Fe}(\mathrm{CN})_{6}$ in alkaline. The titration was conducted three times. The titration results were presented in Table $\mathbf{1 .}$

\section{DISCUSSION}

The ionic liquid [BMIM]Cl was synthesized from 1chlorobutane and 1-methylimidazole in acetonitrile, according to Dupont et al. ${ }^{6}$. The obtained synthetic ionic liquid was examined by ${ }^{1} \mathrm{H}-\mathrm{NMR}$ spectrum. Compare to the published spectroscopic data, and it can be established that the obtained product was 1-butyl-3-methyl-imidazolium chloride [BMIM]Cl. This compound was then used to prepare ionic liquid to extract beta-glucan from the baker's yeast (Saccharomycess cerevisiae). A solution of baker's yeast and [BMIM] Cl (1:20, w/w) was stirred in $30 \mathrm{~min}$ at $80^{\circ} \mathrm{C}$ until all powder absolutely dissolved in [BMIM]Cl. Precipitates were formed in a clear solution when water was added. Pure beta-glucan as white powder was obtained with a yield of about $83.5 \%$ (compared to the beta-glucan amount contained originally in the yeast). Cell wall $\beta$-D-glucans might be divided into two subtypes following the mode of glucose linkages: long chains of ca. $1500 \mathrm{D}$-glucose units linked by $(1 \rightarrow 3)$ glycosidic bonds and short chain of ca. $150(1 \rightarrow 6)-\beta$ D-glucose units, represented of $85 \%$ and $15 \%$ of total cell wall $\beta$-D-glucan, respectively ${ }^{5}$. Titration data 


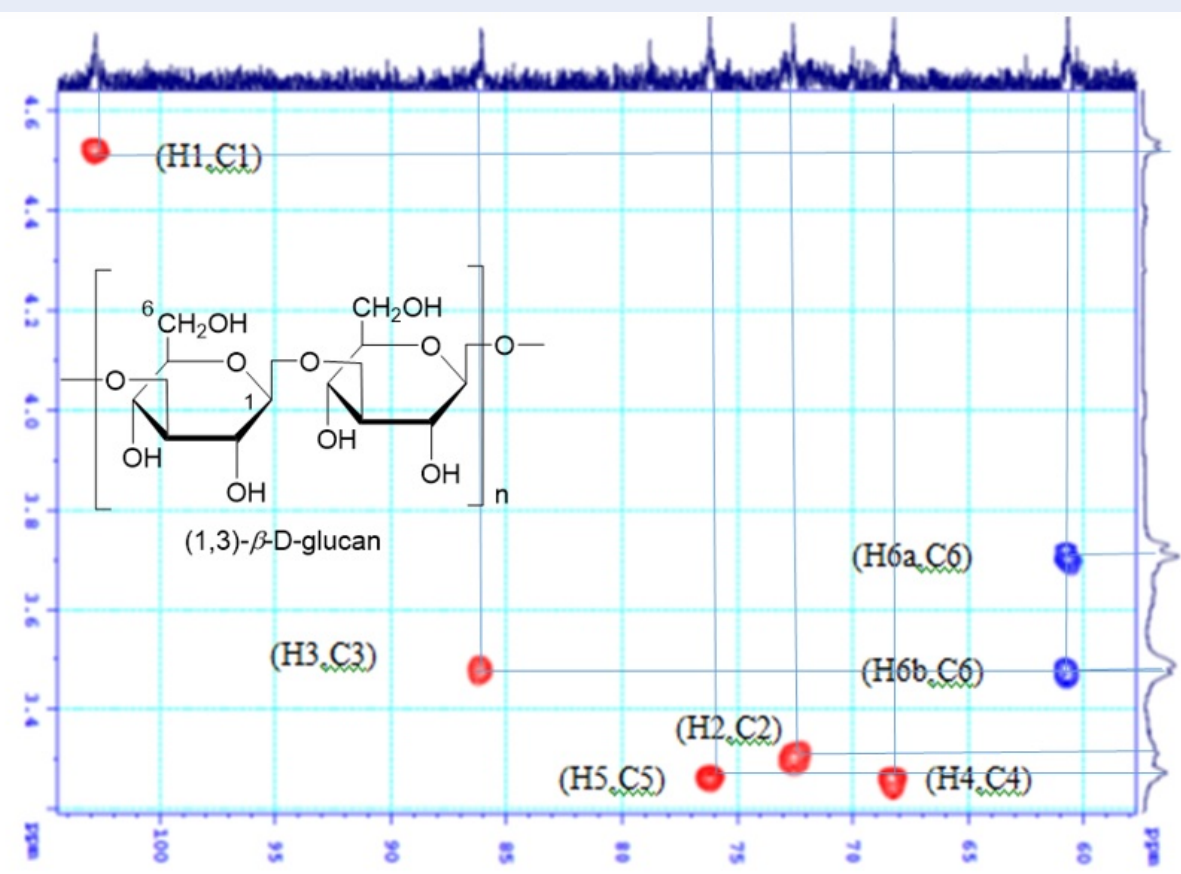

Figure 2: HSQC spectrum (DMSO-d $\mathrm{d}_{6}$ ) of the obtained product 1,3-beta-D-glucan.

Table 1: Determination of glucan content in the product beta-glucan

\begin{tabular}{llllll}
\hline Volume of hydrolyzed beta-glucan $(\mathrm{ml})$ & $\begin{array}{l}1^{\text {st }} \\
(\mathrm{ml})\end{array}$ & $\begin{array}{l}2^{\text {nd }} \\
(\mathrm{ml})\end{array}$ & $\begin{array}{l}3^{\text {rd }} \\
(\mathrm{ml})\end{array}$ & $\begin{array}{l}\text { Average } \\
(\mathrm{ml})\end{array}$ & \% b-glucan \\
$\mathrm{V}_{0}$ (standard sample) & 10.10 & 10.10 & 10.10 & 10.10 & \\
$\mathrm{~V}_{1}$ (yeast sample) & 69.10 & 69.30 & 69.50 & 68.97 & $\mathrm{P} 1=0.98^{*} 10.1 / 68.97=14.3 \%$ \\
$\mathrm{~V}_{2}$ (product sample) & 10.50 & 10.40 & 10.40 & 10.43 & $\mathrm{P} 2=0.98^{*} 10.1 / 10.43=95.2 \%$ \\
\hline
\end{tabular}

with $\mathrm{K}_{3} \mathrm{Fe}(\mathrm{CN})_{6}$ showed that our beta-glucan product obtained from yeast contained $95.2 \% \beta$-D-glucan. The 1D- and 2D- NMR spectroscopic data showed the presence of both 1,6- and 1,3- $\beta$-D-glucan with the proportion ratio was $1.302 / 7$, that means $15.6 \%$ of $\beta$ D-glucan was of $1,6-\beta$-D-glucan, and $84.4 \%$ was 1,3 $\beta$-D-glucan. These facts suggested that the extraction by ionic liquid was rather selectively to obtain $1,3-\beta$ D-glucan.

So far, one of the most used techniques for the extraction of $\beta$-glucan from grains and yeast is based on hot water extraction, with the inclusion of a modification of freeze-thaw cycles, with the application of high temperature, or in a combination of enzymes, acids or alkalis resulted in higher recoveries of $\beta$ glucan $^{4}$. Most of which involves two steps: (1): let the yeast autolyzed the cell wall by the enzymes available in the cell into insoluble fragments containing beta-glucan, mannoprotein, and some chitosan;
(2): remove beta-glucan from impurities like proteins, starches, lipids, minerals, and other cell wall polysaccharides within the product by chemicals, enzymes and physical methods like centrifugation, ultrasound, or high pressure ... ${ }^{11,12}$ in a series of steps are commonly used ${ }^{4}$. However, the isolated beta-glucan from the known methods was usually mixed with impurities of the yeast cell membrane.

Nowadays, ionic liquids are attracted a lot of interest as they possess some very important properties including high polarity, high chemical, and thermal stabilities, etc., that resulted in the ionic liquids could destroy intermolecular hydrogen bonds forming the rigid triple-helix hardly-dissolved structure of yeast $\beta$-D-glucan and therefore could enhance the dissolution of bio-macromolecules including cellulose, lignin, starch, chitosan and wood ${ }^{5}$. Liu et al. reported that by using several ionic liquids like 1-ethyl-3-methylimidazolium acetate (EmimAc), 1- 

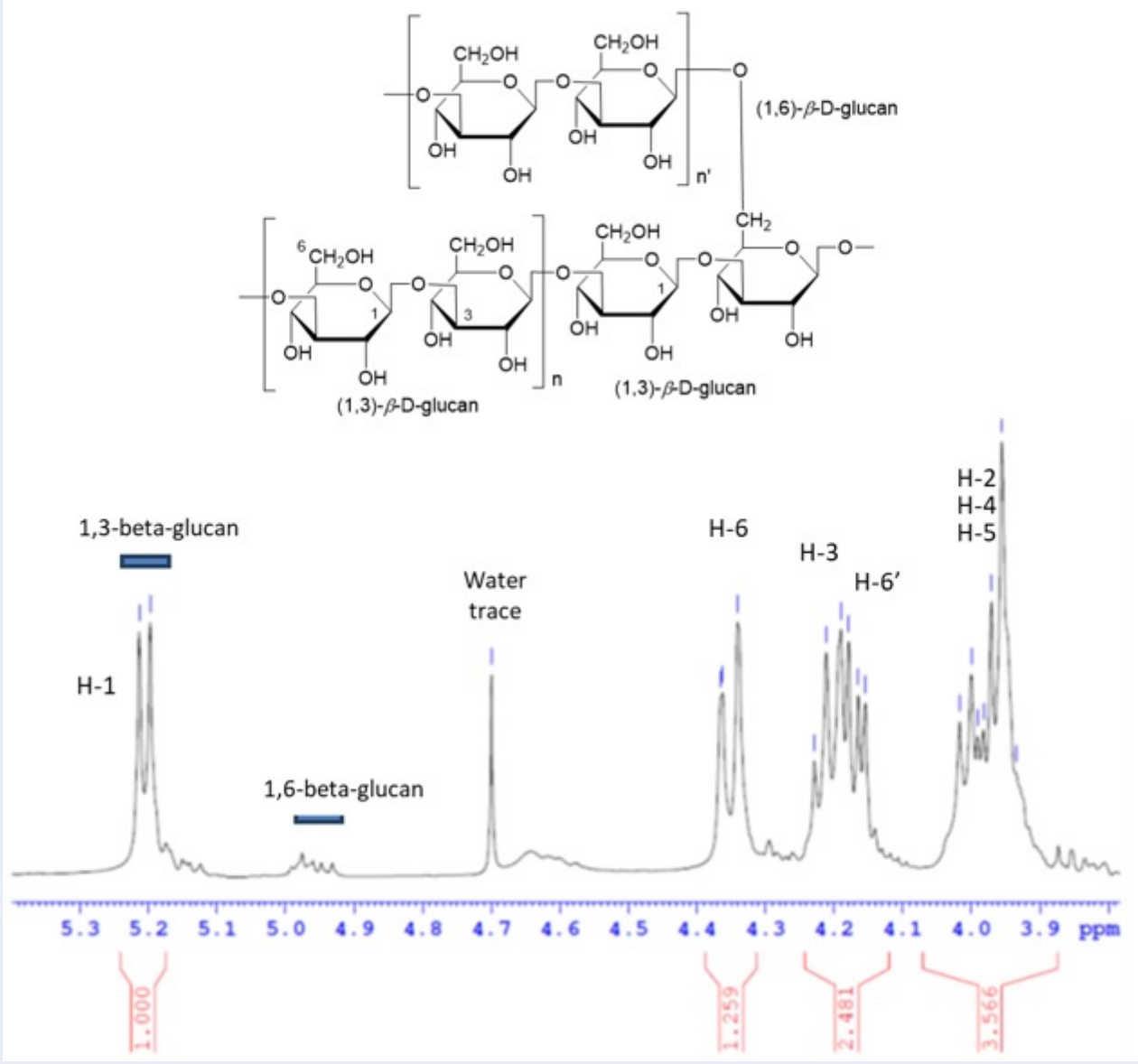

Figure 3: ${ }^{1} \mathrm{H}$-NMR spectrum $\left(\mathrm{CD}_{3} \mathrm{COOD}-\mathrm{d}_{4}\right)$ and the structure of beta-glucan.

butyl-3-methylimidazolium acetate (BmimAc) and 1allyl-3-methylimidazolium chloride (AmimCl) they got $\beta$-D-glucan with the purity of $>81.07 \%{ }^{5}$. From the data presented in Table 1, the amount of $\beta$-Dglucan in our product obtained from baker's yeast using the ionic liquid 1-butyl-3-methyl-imidazolium chloride [BMIM]Cl was $95.2 \%$. It might be because that the $\beta$-D-glucan could completely dissolve in [BMIM]Cl by constant stirring for $30 \mathrm{~min}$ at $80{ }^{\circ} \mathrm{C}$. $\beta$-glucans are biomacromolecular with diversity health-benefit activities like immunomodulatory $^{3}$, anti-cancer ${ }^{3}$, anti-diabetic ${ }^{4}$, anti-viral, antibacteria $^{5}$, anti-hypertensive ${ }^{4}$, and wound healing activities ${ }^{5}$. The production of a high purity $\beta$-D-glucan product could help to be applicable in different fields as food technology, pharmaceutical, and cosmetic technology. However, the use of ionic liquid for extraction of $\beta$-D-glucan from yeast also has many limitations, including toxicity, cost, and difficulties of solvent synthesis and recovery.

\section{CONCLUSIONS}

In this paper, we reported that $\beta$-D-glucan could be extracted from baker yeast $S$. cerevisiae using ionic liquid 1-butyl-3-methyl-imidazolium chloride [BMIM]Cl with the purity of $95.2 \%$, with a yield of about $83.4 \%$ (compared to beta-glucan originally contained in the yeast)... The 1D- and 2D-NMR spectrum results confirmed that the product was the polysaccharides with $\beta$ - $(1 \rightarrow 3)$ glycosidic bonds, with the $\beta$ $(1 \rightarrow 6)$-D-glucan chain $\sim 15.6 \%$. No impurity of mannan carbohydrate was found in the product. The extraction of $\beta$-D-glucan from baker's yeast with the ionic liquid [BMIM] $\mathrm{Cl}$ is a simple method, resulting in the production of a high purity beta-D-glucan product that is applicable in different fields as food technology, pharmaceutical, and cosmetic technology. 


\section{LIST OF ABBREVIATIONS}

[BMIM]Cl - 1-butyl-3-methyl-imidazolium chloride; IUPAC- International Union of Pure and Applied Chemistry; 1D- and 2D-NMR - 1 dimensional and 2-dimensional nuclear magnetic resonance.

\section{AUTHORS' CONTRIBUTIONS}

Dr. Nguyen Duy Nhut was responsible for the experimental design and conduct. Assoc. Prof. Nguyen Manh Cuong revised and corrected the MS. Dr. Pham Ngoc Khanh checked references and prepared the MS. All the authors read and corrected the submitted final MS.

\section{COMPETING INTEREST}

The author(s) declare that they have no competing interests.

\section{ACKNOWLEDGEMENTS}

This work is funded by the Vietnam Academy of Science and Technology through project No.VAST04.04/17-18 and Ministry of Industry and Trade through project No.030/2019/HĐ-DA.CNHD.

\section{REFERENCES}

1. Nair AV, Gummadi SN, Doble M. Process optimization and kinetic modelling of cyclic $(1 \rightarrow 3,1 \rightarrow 6)$ - $\beta$-glucans production from Bradyrhizobium japonicum MTCC120. Journal of Biotechnology. 2016;226:35-43. PMID: 27046066. Available from: https://doi.org/10.1016/j.jbiotec.2016.03.055.

2. Mason R. What is beta-glucan: Safe Goods; 2 edition. 2001;.

3. Akramiene D, Kondrotas A, Didziapetriene J, Kevelaitis E. Effects of beta-glucans on the immune system. Medicina (Kau- nas, Lithuania). 2007;43(8):597-606. Available from: https: //doi.org/10.3390/medicina43080076.

4. Ahmad A, Kaleem M. Chapter 11 - $\beta$-Glucan as a Food Ingredient. In: Grumezescu AM, Holban AM, editors. Biopolymers for Food Design: Academic Press. 2018;p. 351-381. Available from: https://doi.org/10.1016/B978-0-12-811449-0.00011-6.

5. Liu H, Li Y, Gao J, Shi A, Liu L, Hu H, et al. Effects of microfluidization with ionic liquids on the solubilization and structure of $\beta$ d-glucan. International Journal of Biological Macromolecules. 2016;84:394-401. PMID: 26691385. Available from: https: //doi.org/10.1016/j.ijbiomac.2015.12.014.

6. Dupont J, Consorti CS, Suarez PAZ, F. dSR. Preparation of 1Butyl-3-Methyl Imidazolium-Based Room Temperature Ionic Liquids. Org Synth. 2002;79(236). Available from: https://doi. org/10.15227/orgsyn.079.0236.

7. Schmidt CF. Determination of Carbohydrates in Bacteriological Culture Media. J Bacteriol. 1931;22(1):31-48. PMID: 16559503. Available from: https://doi.org/10.1128/JB.22.1.3148.1931.

8. Ohno N, Uchiyama M, Tsuzuki A, Tokunaka K, Miura NN, Adachi $\mathrm{Y}$, et al. Solubilization of yeast cell-wall $\beta-(1 \rightarrow 3)$-d-glucan by sodium hypochlorite oxidation and dimethyl sulfoxide extraction. Carbohydrate Research. 1999;316(1):161-172. Available from: https://doi.org/10.1016/S0008-6215(99)00049-X.

9. Kono H, Kondo N, Hirabayashi K, Ogata M, Totani K, Ikematsu S, et al. Two-dimensional NMR data of a water-soluble $\beta$ - $(1 \rightarrow 3$ $1 \rightarrow 6)$-glucan from Aureobasidium pullulans and schizophyllan from Schizophyllum commune. Data Brief. 2017;15:382388. PMID: 29854896. Available from: https://doi.org/10.1016/ j.dib.2017.09.067.

10. Amaya-González S, de-Los-Santos-Álvarez N, MirandaOrdieres AJ, Lobo-Castañón MJ. Sensitive gluten determination in gluten-free foods by an electrochemical aptamer-based assay. Anal Bioanal Chem. 2015;407(20):6021-6029. PMID: 26048055. Available from: https://doi.org/10.1007/s00216-015-8771-6.

11. Sedmak J, inventor; SENSIENT FLAVORS LLC, assignee. Production of beta-glucans and mannans. USA. 2005;

12. Naruemon $M$, Romanee $S$, Cheunjit $P$, Xiao $H$, McLands borough LA, Pawadee M. Influence of additives on Saccharomyces cerevisiae $\beta$-glucan production. Int Food Res J. 2013;20(4):1953-1959. 